\title{
Impact of China's high speed train window glass on GNSS signals and positioning performance
}

Zhizhao Liu ${ }^{1,2^{*}}$ (D) Yangzhao Gong ${ }^{1,2}$ and Letao Zhou ${ }^{3}$

\begin{abstract}
High speed train (HST) is an excellent platform to perform ultra-high spatial and temporal resolution observations of atmosphere using global navigation satellite systems (GNSS). However, we find that signal attenuation caused by HST window glass is a major barrier for HST-based GNSS applications inside HST chambers. A field experiment is conducted to analyze the effect of HST glass on GNSS signal propagation. In the experiment, GNSS observations are collected and analyzed from a receiver covered with an HST window glass and one with an open-sky view. The size of the HST window glass is $670 \mathrm{~mm} \times 720 \mathrm{~mm}$, with a thickness of $34 \mathrm{~mm}$. The window glass is a double-glazing glass in which each layer has an actual thickness of $6 \mathrm{~mm}$, and the two layers are separated by an air gap of $22 \mathrm{~mm}$. The experiment results indicate that HST window glass can cause significant degradation to GNSS signals and even loss of tracking of the signal. Based on statistical results, HST window glass causes 39\%, 56\%, 49\%, and 59\% loss in GPS, GLONASS, Galileo, and BDS signals, respectively. Additionally, up to $20 \mathrm{~dB}-\mathrm{Hz}$ of carrier-to-noise ratio $\left(\mathrm{C} / \mathrm{N}_{0}\right)$ degradation is also observed in the remaining observations. The significant signal attenuation and loss further lead to the decrease in the number of tracked satellites and occurrence of more cycle slips. The results of the study indicate that 44-230 cycle slips are detected for the HST glass-covered receiver whereas the receiver without glass does not exhibit more than 16 cycle slips. Additionally, the number of GNSS satellites tracked by the HST glass-covered receiver is reduced by $65 \%$ owing to the loss of signal. Furthermore, GNSS positioning performances from two receivers are also tested. With respect to GPS + GLONASS static precise point positioning (PPP), HST glass causes a degradation of $1.516 \mathrm{~m}$ and $1.159 \mathrm{~m}$ in the single-frequency and dual-frequency three-dimensional positioning accuracy, respectively. With respect to the GPS + GLONASS kinematic PPP, the accuracy degradations for single-frequency and dual-frequency kinematic PPP are $2.670 \mathrm{~m}$ and $4.821 \mathrm{~m}$, respectively.
\end{abstract}

Keywords: Global navigation satellite systems (GNSS), High-speed train (HST) window glass, Signal attenuation and loss

\section{Introduction}

Ionosphere and troposphere are important layers of the atmosphere that significantly affect many Earth observation systems. With respect to global navigation satellite systems (GNSS) navigation and positioning, the signal

\footnotetext{
*Correspondence: Iszzliu@polyu.edu.hk

${ }^{1}$ Department of Land Surveying and Geo-Informatics (LSGI), The Hong Kong Polytechnic University (PolyU), 181 Chatham Road South, Hung Hom, Kowloon, Hong Kong, People's Republic of China

Full list of author information is available at the end of the article
}

delay owing to the ionosphere and troposphere can range up to approximately $30 \mathrm{~m}$ and $2.6 \mathrm{~m}$, respectively, in the zenith direction. Hence, they are key factors in limiting positioning performance (Bock and Doerflinger 2001; Hernández-Pajares et al. 2009). Some extreme atmosphere cases, such as ionospheric scintillation, can cause signal degradation and even loss of tracking of GNSS signals (Yang and Liu 2016). Thus, an interesting research topic in the area of GNSS is monitoring and modeling the atmosphere, including the troposphere and ionosphere. 
In order to monitor and model atmosphere, Liu et al. (2016) proposed using a high-speed train (HST) as a new observation platform. By deploying a GNSS receiver on a fast-moving train, many observations with an ultra-high spatial and temporal resolution are obtained, which can be used for various research purposes including atmospheric modeling. A GNSS receiver deployed on a highspeed train can make atmospheric observations with a spatial resolution of $83 \mathrm{~m}$ at a regular sampling rate of $1 \mathrm{~Hz}$ because the typical traveling speed of a HST in China is approximately $300 \mathrm{~km} / \mathrm{h}$. It is not possible to achieve this level of spatial resolution using the traditional continuously operating reference stations (CORS) technique for atmospheric observation.

However, there are many challenging problems to obtain high quality GNSS observations on fast-moving trains. A practical obstacle is the signal attenuation and blockage by the HST window glass, which is the topic of the present study. In 2017, we performed a test on a highspeed train by placing a Trimble R10 GNSS receiver near the window of the HST chamber. However, the results indicated that the receiver failed to output GNSS positioning solutions. Thus, we suspected that the window glass of the HST significantly blocks the GNSS signal. A literature review revealed a paucity of studies on the topic. The extent to which the HST window glass affects GNSS signals is not understood.

However, for the other types of glasses (non-HST window glass), several studies were performed to assess their effect on GNSS signal propagation (Ängskog et al. 2015; Asp et al. 2012; Kjærgaard et al. 2010; Seco-Granados et al. 2012; Stone 1997). An early study indicated that the attenuation of GNSS electromagnetic signals due to glass increases with increases in glass thickness. With respect to GPS L1 band (1575.42 MHz), a piece of 6-19$\mathrm{mm}$ thick ordinary architectural window glass can cause an electromagnetic signal attenuation ranging from 1 to $4 \mathrm{~dB}$ (Stone 1997). When compared with the traditional clear glass, other types of glasses, such as coated glass, energy-efficient glass, and tinted glass, can lead to a significantly higher level of degradation on GNSS signals. For example, Ängskog et al. (2015) suggested that different types of coated glasses can cause a range of attenuation from 10 to $30 \mathrm{~dB}$ for $1-18 \mathrm{GHz}$ radio signals. Asp et al. (2012) assessed attenuation values for a piece of 4-layered energy-efficient window, which included a double double-glazing glass with metal shielding layers. The results indicated that an attenuation of approximately $27 \mathrm{~dB}$ was measured at a frequency of approximately $1500 \mathrm{MHz}$. It should be noted that attenuation was mainly attributed to the metal shielding layers. Widenberg and Rodriguez (2002) tested influence of different glass plates, i.e., no glass plate, a single glass plate, and a double glass plate with metallic shielding, on signal transmission at $1800 \mathrm{MHz}$. They indicated that attenuation values were insignificant in the case of no glass plate or a single glass plate while a double glass plate with metallic shielding resulted in an attenuation of $20 \mathrm{~dB}$. Additionally, an attenuation of 24.44 dB in GPS L1 band signals due to shopping mall tinted glass was reported in an indoor positioning study (Kjærgaard et al. 2010).

The previous studies demonstrated that different types of glasses can cause GNSS signal degradation to different degrees. It is expected that the signal attenuation caused by the aforementioned glasses and HST glass will be different given the difference in materials and manufacturing process. A field experiment is conducted to assess the effect of HST glass on GNSS signals. The experiment results are detailed and discussed in the following sections.

The rest of the study is organized as follows. First, the details of experiment are described in the "Experiment description and data collection" section. Next, GNSS signals are analyzed with respect to various assessment indicators. Finally, a few conclusions are summarized.

\section{Experiment description and data collection}

The experiment was conducted on a building rooftop on the campus of Southwest Jiaotong University, Chengdu, China on 9 March 2019, as shown in Fig. 1. Two Trimble R10 GNSS receivers were deployed closely for comparison purposes. The GNSS data sampling rate was set as $1 \mathrm{~Hz}$ and the signal cutoff angle was set to $0^{\circ}$. In the experiment, data were collected in two periods. During period 1 (GPS time: 3:00:00-9:00:00), receiver 1 was

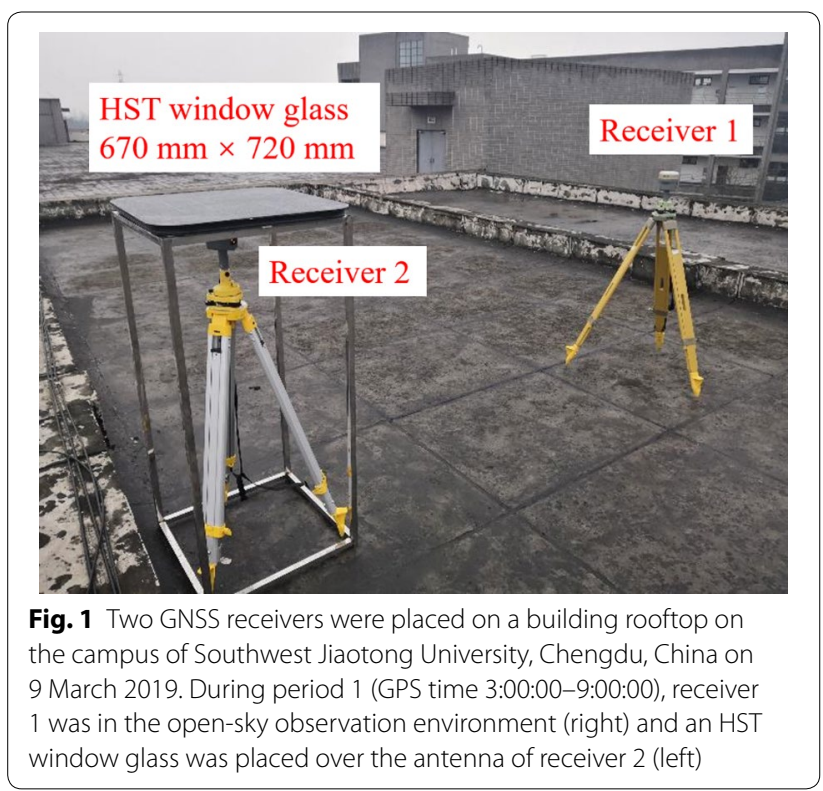


placed in an open-sky environment but receiver 2 (and its antenna) was covered by a piece of HST window glass of size $670 \mathrm{~mm}$ by $720 \mathrm{~mm}$. It is a double-glazing glass, each layer with a thickness of $6 \mathrm{~mm}$, and the two layers are separated by an air gap of $22 \mathrm{~mm}$. The glass is identical to the window glass installed on high speed trains, which are widely in operation in China. We adjusted the height of the tripod of receiver 2 so that the separation between the glass and top of the antenna of receiver 2 is minimal. In period 2 (GPS time: 11:00:00-14:00:00), the HST window glass over the receiver 2 was removed and both receivers were placed in an open-sky environment. The GNSS observation types and related details of two receivers are listed in Table 1.

It should be noted that we conducted a GNSS test in a real situation on a high-speed train. We performed a test on August 10, 2017 by placing a Trimble R10 GNSS receiver inside the train's chamber beside the chamber's window glass on a high-speed train traveling between the city of Shenzhen, China and the city of Changsha, China. The results indicated that the receiver unfortunately failed to track GNSS satellites inside the chamber. Thus, GNSS data from real high speed train are not available for analysis and evaluation purposes.

\section{Assessment and analysis of GNSS signals}

In this section, we mainly analyze the GNSS signal attenuation due to the HST glass as observed by receiver 2 when compared with that of the reference receiver 1 . The performance degradation of receiver 2 , in terms of signal integrity, carrier-to-noise ratio $\left(C / N_{0}\right)$, cycle slip, total electron contents rate (TECR), number of tracked satellites, precise point positioning (PPP) performance, geometric dilution of precision (GDOP), is examined in the study.

\section{Analysis of signal integrity}

Given the significant attenuation caused by the HST glass, many GNSS signals are excessively weak to be tracked by GNSS receiver. The number of signal losses is measured by a parameter termed as signal integrity. In the study, only pseudorange observations are used in the statistics. Tracking of carrier phase signals is more vulnerable to locking of pseudorange data. Thus, it is assumed that once pseudorange observation is lost, the corresponding carrier phase observation at the same frequency is also lost. Therefore, only the pseudorange observation is considered.

The availabilities of pseudorange signals for GPS C2W, GLONASS C1C, Galileo C1X, BDS C2I during period 1 are shown in Fig. 2. Overall, it is evident that the number of GPS/GLONASS/Galileo/BDS signals tracked by receiver 1 (in the open-sky environment) significantly exceeds that of receiver 2 (covered by an HST window glass). Specifically, for GPS C2W, only a small part of the signals is tracked by receiver 2 . Additionally, as shown in Fig. 2, nearly all of the signals from BDS C01-C05 satellites (GEO satellites) are lost by receiver 2 . A potential reason is that the orbit height of GEO satellite $(\sim 36,000 \mathrm{~km})$ significantly exceeds that of other types of satellites, i.e., MEO satellites. The orbit heights of MEO satellites approximately are $20,200 \mathrm{~km}, 19,100 \mathrm{~km}$, and 23,222 $\mathrm{km}$ for GPS, GLONASS, and Galileo, respectively. High satellite orbit for GEO indicates that the signals emitted from these satellites are weaker than those from MEO satellites. Given the placement of HST window glass over the receiver 2, most GEO satellite signals are blocked by the glass.

Table 2 summarizes the statistics of the number of pseudorange observations for GPS/GLONASS/Galileo/ BDS for both receivers in both periods. Table 2 shows that during period 1 , many signals of receiver 2 are lost. When compared with the number of observations of receiver 1 , the average signal loss rates of receiver 2 in period 1 are 39\%, 56\%, 49\%, and 59\% for GPS, GLONASS, Galileo, and BDS, respectively. Specifically, the loss rate of GPS C2W signal reaches $82 \%$. A potential reason is that the channel of $\mathrm{C} 2 \mathrm{~W}$ uses $\mathrm{Z}$-tracking under anti-spoofing or similar techniques (Gurtner and Estey 2013).

Table 1 GNSS observation types and the details of the two receivers

\begin{tabular}{lll}
\hline & Receiver $\mathbf{1}$ & Receiver $\mathbf{2}$ \\
\hline Period 1 (GPS time: 3:00:00-9:00:00) & Without glass & With glass \\
Period 2 (GPS time: 11:00:00-14:00:00) & Without glass & Without glass \\
Antenna type & TRMR10 NONE & GPS: C1C/L1C, C2W/L2W, C2X/L2X, C5X/L5X \\
Observation types & GLONASS: C1C/L1C,C1P/L1P, C2C/L2C, C2P/L2P, C3X/L3X \\
& Galileo: C1X/L1X,C5X/L5X, C7X/L7X, C8X/L8X \\
& BDS: C2I/L2I, C7I/L7I \\
\hline
\end{tabular}



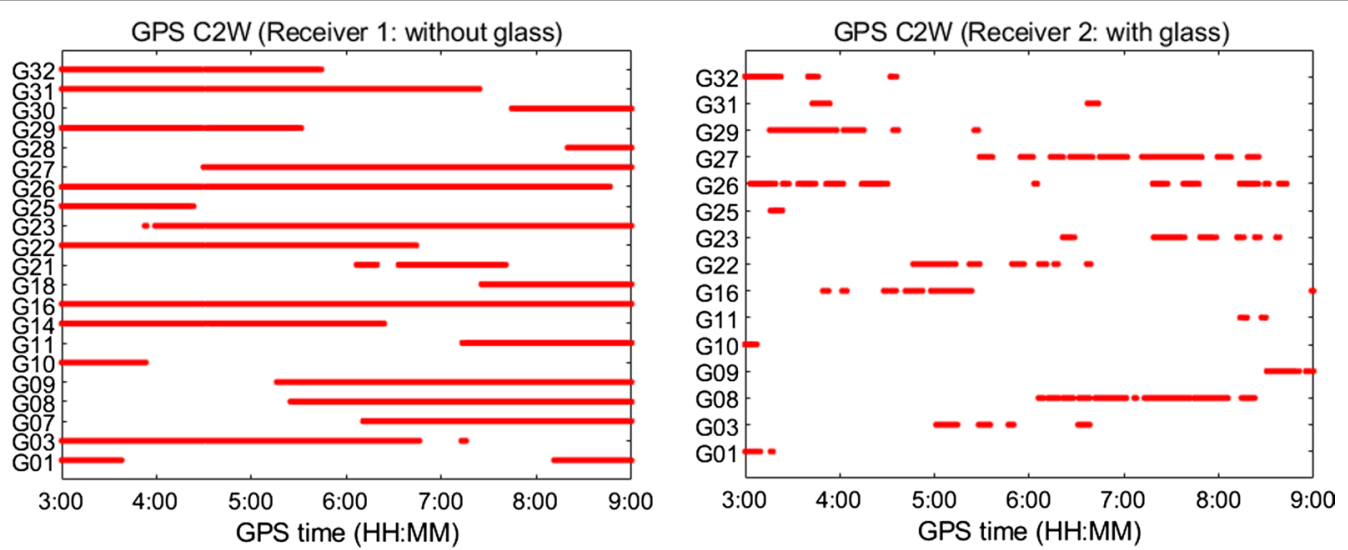

GLONASS C1C (Receiver 1: without glass)
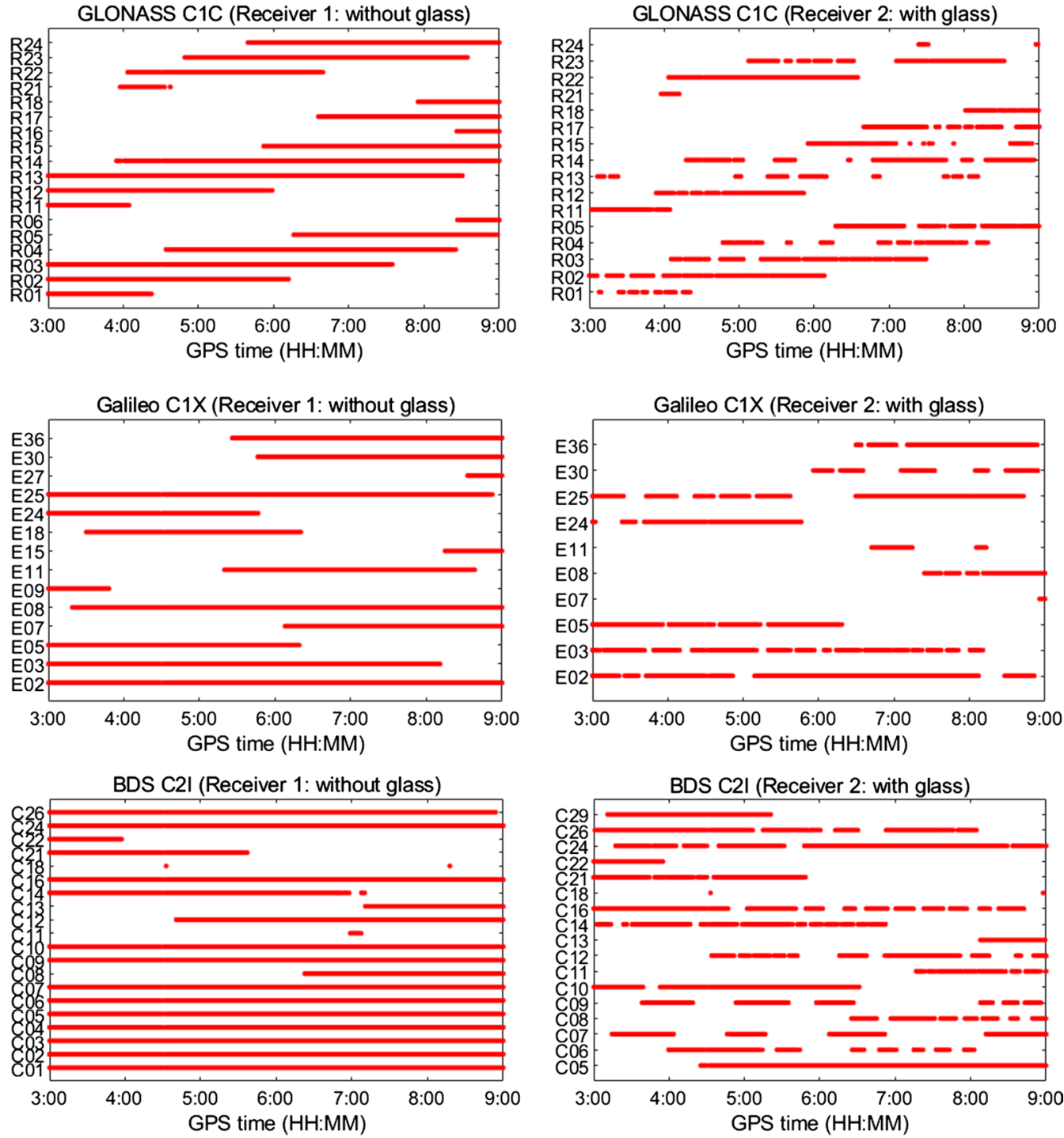

Fig. 2 Availability of pseudorange observations for GPS C2W, GLONASS C1C, Galileo C1X, and BDS C2I for each GNSS satellite tracked by receiver 1 (left column, without HST window glass) and receiver 2 (right column, with HST window glass) deployed on a building rooftop on the campus of Southwest Jiaotong University, Chengdu, China, 9 March 2019 
Table 2 Number of different types of pseudorange observations as tracked by the two receivers during the two periods

\begin{tabular}{|c|c|c|c|c|c|c|c|c|}
\hline \multirow[t]{2}{*}{ GNSS } & \multirow{2}{*}{$\begin{array}{l}\text { Code } \\
\text { of observation } \\
\text { type }\end{array}$} & \multirow{2}{*}{$\begin{array}{l}\text { Band/Frequency } \\
(\mathrm{MHz})\end{array}$} & \multicolumn{3}{|c|}{ Period 1 (GPS time: 3:00:00-9:00:00) } & \multicolumn{3}{|c|}{ Period 2 (GPS time: 11:00:00-14:00:00) } \\
\hline & & & $\begin{array}{l}\text { Receiver } 1 \\
\text { (without } \\
\text { glass) }\end{array}$ & $\begin{array}{l}\text { Receiver } 2 \\
\text { (with glass) }\end{array}$ & $\begin{array}{l}\text { Average } \\
\text { rate }\end{array}$ & $\begin{array}{l}\text { Receiver } 1 \\
\text { (without } \\
\text { glass) }\end{array}$ & $\begin{array}{l}\text { Receiver } 2 \\
\text { (without } \\
\text { glass) }\end{array}$ & Average rate \\
\hline \multirow[t]{4}{*}{ GPS } & $\mathrm{C} 1 \mathrm{C}$ & $\mathrm{L} 1 / 1575.420$ & 227,452 & $\begin{array}{c}190,193 \\
(84 \% \\
16 \%)\end{array}$ & & 120,693 & $\begin{array}{l}119,237 \\
(99 \%, 1 \%)\end{array}$ & $(98 \%, 2 \%)$ \\
\hline & $\mathrm{C} 2 \mathrm{~W}$ & L2/1227.600 & 223,507 & $\begin{array}{l}39,551(18 \%, \\
82 \%)\end{array}$ & $(61 \%, 39 \%)$ & 118,581 & $\begin{array}{l}116,101 \\
(98 \%, 2 \%)\end{array}$ & \\
\hline & $\mathrm{C} 2 \mathrm{X}$ & L2/1227.600 & 140,596 & $\begin{array}{c}105,785 \\
(75 \% \\
25 \%)\end{array}$ & & 65,885 & $\begin{array}{l}64,870(98 \%, \\
2 \%)\end{array}$ & \\
\hline & C5X & L5/1176.450 & 105,339 & $\begin{array}{l}87,178(83 \%, \\
17 \%)\end{array}$ & & 48,777 & $\begin{array}{l}47,860(98 \%, \\
2 \%)\end{array}$ & \\
\hline \multirow[t]{5}{*}{$\begin{array}{l}\text { GLONASS } \\
\qquad(\mathrm{k}=-7 \ldots+12)\end{array}$} & $\mathrm{C} 1 \mathrm{C}$ & $\mathrm{G} 1 / 1602+k^{*} 9 / 16$ & 172,475 & $\begin{array}{l}87,227(51 \%, \\
49 \%)\end{array}$ & & 81,157 & $\begin{array}{l}79,352(98 \%, \\
2 \%)\end{array}$ & $(98 \%, 2 \%)$ \\
\hline & $\mathrm{C} 1 \mathrm{P}$ & $\mathrm{G} 1 / 1602+k^{*} 9 / 16$ & 172,050 & $\begin{array}{l}78,895(46 \%, \\
54 \%)\end{array}$ & $(44 \%, 56 \%)$ & 81,008 & $\begin{array}{l}79,332(98 \%, \\
2 \%)\end{array}$ & \\
\hline & $\mathrm{C} 2 \mathrm{C}$ & $G 2 / 1246+k^{*} 7 / 16$ & 159,989 & $\begin{array}{l}69,583(43 \%, \\
57 \%)\end{array}$ & & 81,114 & $\begin{array}{l}79,343(98 \%, \\
2 \%)\end{array}$ & \\
\hline & $\mathrm{C} 2 \mathrm{P}$ & $G 2 / 1246+k^{*} 7 / 16$ & 159,316 & $\begin{array}{l}57,263(36 \%, \\
64 \%)\end{array}$ & & 81,070 & $\begin{array}{l}79,290(98 \%, \\
2 \%)\end{array}$ & \\
\hline & $\mathrm{C} 3 \mathrm{X}$ & G3/1202.025 & 1155 & $\begin{array}{l}\text { No observa- } \\
\text { tion }\end{array}$ & & 607 & $\begin{array}{l}668(110 \% \\
0 \%)\end{array}$ & \\
\hline \multirow[t]{4}{*}{ Galileo } & $\mathrm{C} 1 \mathrm{X}$ & $\mathrm{E} 1 / 1575.420$ & 167,055 & $\begin{array}{l}86,563(52 \%, \\
48 \%)\end{array}$ & & 75,531 & $\begin{array}{l}75,465 \\
(100 \% \\
0 \%)\end{array}$ & $(100 \%, 0 \%)$ \\
\hline & C5X & $\mathrm{E} 5 \mathrm{a} / 1176.450$ & 167,008 & $\begin{array}{l}85,472(51 \%, \\
49 \%)\end{array}$ & $(51 \%, 49 \%)$ & 75,510 & $\begin{array}{l}75,457 \\
(100 \% \\
0 \%)\end{array}$ & \\
\hline & $C 7 X$ & $\mathrm{E} 5 \mathrm{~b} / 1207.140$ & 167,008 & $\begin{array}{l}84,669(51 \%, \\
49 \%)\end{array}$ & & 75,510 & $\begin{array}{c}75,457 \\
(100 \% \\
0 \%)\end{array}$ & \\
\hline & $\mathrm{C} 8 \mathrm{X}$ & E5 $(E 5 a+E 5 b) / 1191.795$ & 167,008 & $\begin{array}{l}86,059(52 \% \\
48 \%)\end{array}$ & & 75,510 & $\begin{array}{l}75,457 \\
(100 \% \\
0 \%)\end{array}$ & \\
\hline \multirow[t]{2}{*}{ BDS } & $\mathrm{C} 2 \mathrm{I}$ & B1/1561.098 & 316,515 & $\begin{array}{c}153,812 \\
(47 \% \\
53 \%)\end{array}$ & & 117,439 & $\begin{array}{l}116,528 \\
(99 \%, 1 \%)\end{array}$ & $(99 \%, 1 \%)$ \\
\hline & $C 71$ & B2/1207.140 & 261,148 & $\begin{array}{l}82,080(31 \%, \\
69 \%)\end{array}$ & $(41 \%, 59 \%)$ & 116,374 & $\begin{array}{l}115,251 \\
(99 \%, 1 \%)\end{array}$ & \\
\hline
\end{tabular}

In each pair of parentheses, the first number denotes the percentage of observations of receiver 2 with respect to receiver 1 and the second number denotes the percentage of data loss of receiver 2

Table 2 suggests that the two receivers observe almost equal number of observations during period 2 when both of them are in the same open-sky observation condition (the glass over receiver 2 has been removed) during data collection. This implies that both receivers exhibit the same performance and both track the same number of observations under the same observing condition. Therefore, it is reasonable to use receiver 1 as a reference to evaluate the performance of receiver 2 when the HST window glass is placed over the antenna of receiver 2 in period 1 .

\section{Analysis of $\mathrm{C} / \mathrm{N}_{0}$}

The GNSS signal $\mathrm{C} / \mathrm{N}_{0}$ is an important parameter that is usually used to assess GNSS signal quality (Zhang et al. 2017). Given the strong positive relationship between $C / \mathrm{N}_{0}$ and elevation angle, we obtain average $\mathrm{C} / \mathrm{N}_{0}$ statistics for each elevation angle interval of $10^{\circ}$ (i.e., $\left.0^{\circ}-10^{\circ}, 10^{\circ}-20^{\circ}, \ldots 80^{\circ}-90^{\circ}\right)$. The average $\mathrm{C} / \mathrm{N}_{0}$ for different types of GNSS signals during the two periods are shown in Fig. 3. Overall, the average $\mathrm{C} / \mathrm{N}_{0}$ of receiver 1 exceeds that of receiver 2 during the period 1 as shown in the top panel Fig. 3a while they are nearly 
identical during period 2 as shown in the middle panel Fig. 3b.

Specifically, as shown in Fig. 3a, during period 1, the average $C / \mathrm{N}_{0}$ of receiver 1 increases with the increase in elevation angles while the average $C / \mathrm{N}_{0}$ of receiver 2 essentially levels off. At high elevation angles $\left(70^{\circ}-90^{\circ}\right)$, the $\mathrm{C} / \mathrm{N}_{0}$ levels of some observations of receiver 2 are even lower than those at the low elevation angles. This is more evident for GLONASS, Galileo, and BDS observations. A genuine reason for the phenomenon is unknown at this stage and further investigation is still needed.

It should be noted that $\mathrm{C} / \mathrm{N}_{0}$ of GLONASS C3X is not given because the number of observations is excessively low. Specifically, $\mathrm{C} / \mathrm{N}_{0}$ of GPS C2X or C5X is absent at $70^{\circ}-90^{\circ}$ of elevation angle interval during period 2 . In the same period, $\mathrm{C} / \mathrm{N}_{0}$ of GPS C1C and C2W at $80^{\circ}-90^{\circ}$ are also absent during period 2.

Differences in average $C / \mathrm{N}_{0}$ between the two receivers during period 1 are also shown in Fig. 3c. The remaining observations of the receiver 2 (with HST window glass) experience signal strength degradation up to approximately $20 \mathrm{~dB}-\mathrm{Hz}$. Simultaneously, we note that GPS C2W exhibits the largest signal strength degradation. The situation is consistent with the loss rate of $\mathrm{C} 2 \mathrm{~W}$ shown in the part of signal integrity analysis in "Analysis of signal integrity" section.

\section{Analysis of cycle slips}

Cycle slip is a major problem that should be carefully addressed for carrier phase observation users. Frequent cycle slips significantly affect positioning results and convergence time of carrier phase ambiguity resolution. Occurrence of cycle slips can be attributed to the degradation in signal quality and loss of signal tracking. Therefore, the number of cycle slips can be used as a signal quality indicator. In the test, an automated cycle slip detection method is applied to detect cycle slip using different observation combinations (Liu 2011). The observation combinations and corresponding cycle slip statistics are listed in Table 3. Given the significant degradation in $\mathrm{C} / \mathrm{N}_{0}$ of GNSS observations in receiver 2 during period 1 , the number of detected cycle slips for different observation combinations in receiver 2 varies in the range of 44-230. This significantly exceeds those in receiver 1 in which the number of cycle slips varies in the range of 4-16.

\section{Analysis of TECR}

Ionospheric TECR is an indicator that reflects both the variation in the ionosphere and measurement noises. The contribution of ionospheric variation to TECR is extremely low at high cut-off elevation angles and under quiet ionosphere condition. Therefore, it can be used to measure the noise level of GNSS observations under quiet ionosphere activity. In the test, the cut-off elevation angle for TECR is set as $30^{\circ}$. Specifically, TECR is calculated using pseudorange and phase observations (Liu and Gao 2004):

$$
\begin{gathered}
\operatorname{TECR}_{P}(k)=\frac{f_{1}^{2}\left[P_{1}^{j}(k)-P_{2}^{j}(k)-P_{1}^{j}(k-1)+P_{2}^{j}(k-1)\right]}{40.28 \times 10^{16}(1-\gamma) \Delta t} \\
\operatorname{TECR}_{\varphi}(k)=\frac{f_{1}^{2}\left[\varphi_{1}^{j}(k)-\varphi_{2}^{j}(k)-\varphi_{1}^{j}(k-1)+\varphi_{2}^{j}(k-1)\right]}{40.28 \times 10^{16}(\gamma-1) \Delta t}
\end{gathered}
$$

where the $p$ and $\phi$ denote the pseudorange and carrier phase in meters, respectively, and $f_{1}$ and $f_{2}$ denote the frequencies of observations of L1 and L2 signals, respectively. Furthermore, $\gamma=f_{1}^{2} / f_{2}^{2} . \Delta \mathrm{t}$ is the time interval between two consecutive epochs in seconds. In the study, the sampling rate of observations is $1 \mathrm{~s}$. Cycle slips are repaired using an effective cycle slip repair method prior to calculating TECR (Liu 2011).

Figure 4 shows the TECR of pseudorange and carrier phase using GPS $\mathrm{C} 1 \mathrm{C}-\mathrm{C} 2 \mathrm{~W} / \mathrm{L} 1 \mathrm{C}-\mathrm{L} 2 \mathrm{~W}$, GLONASS C1C-C2C/L1C-L2C, Galileo C1X-C5X/L1X-L5X, and BDS C2I-C7I/L2I-L7I during two periods. Over period 1, the TECR values derived from receiver 2's pseudoranges (as shown in Fig. 4a) and carrier phase data (as shown in Fig. 4b) are larger than those of receiver 1. This indicates that GNSS observations of receiver 2 exhibit higher observation noises. Conversely, TECR of two receivers exhibit a good agreement over period 2 when no HST glass is used, as shown in Fig. 4c, d, for pseudorange observations and carrier phase observations, respectively.

The root mean squares (RMS) of TECR for different observation combinations of two GNSS receivers during the two test periods are listed in Table 4. Evidently, during period 1 , the RMS of TECR for receiver 2 exceed those of receiver 1 .

(See figure on next page.)

Fig. 3 Average $C / N_{0}$ at different elevation angles for GPS, GLONASS, Galileo, and BDS for GNSS receiver 1 and receiver 2. a Average C/No at different elevation angles for GPS, GLONASS, Galileo, and BDS during period 1 at receiver 1 (without glass, blue line and marker) and receiver 2 (with glass, red line and marker); $\mathbf{b}$ average $\mathrm{C} / \mathrm{N}_{0}$ at different elevation angles for GPS, GLONASS, Galileo, and BDS during period 2 at receiver 1 (without glass, blue line and marker) and receiver 2 (without glass, red line and marker); c difference in average $C / N_{0}$ for GPS, GLONASS, Galileo, and BDS between two receivers at different elevation angles during period 1 

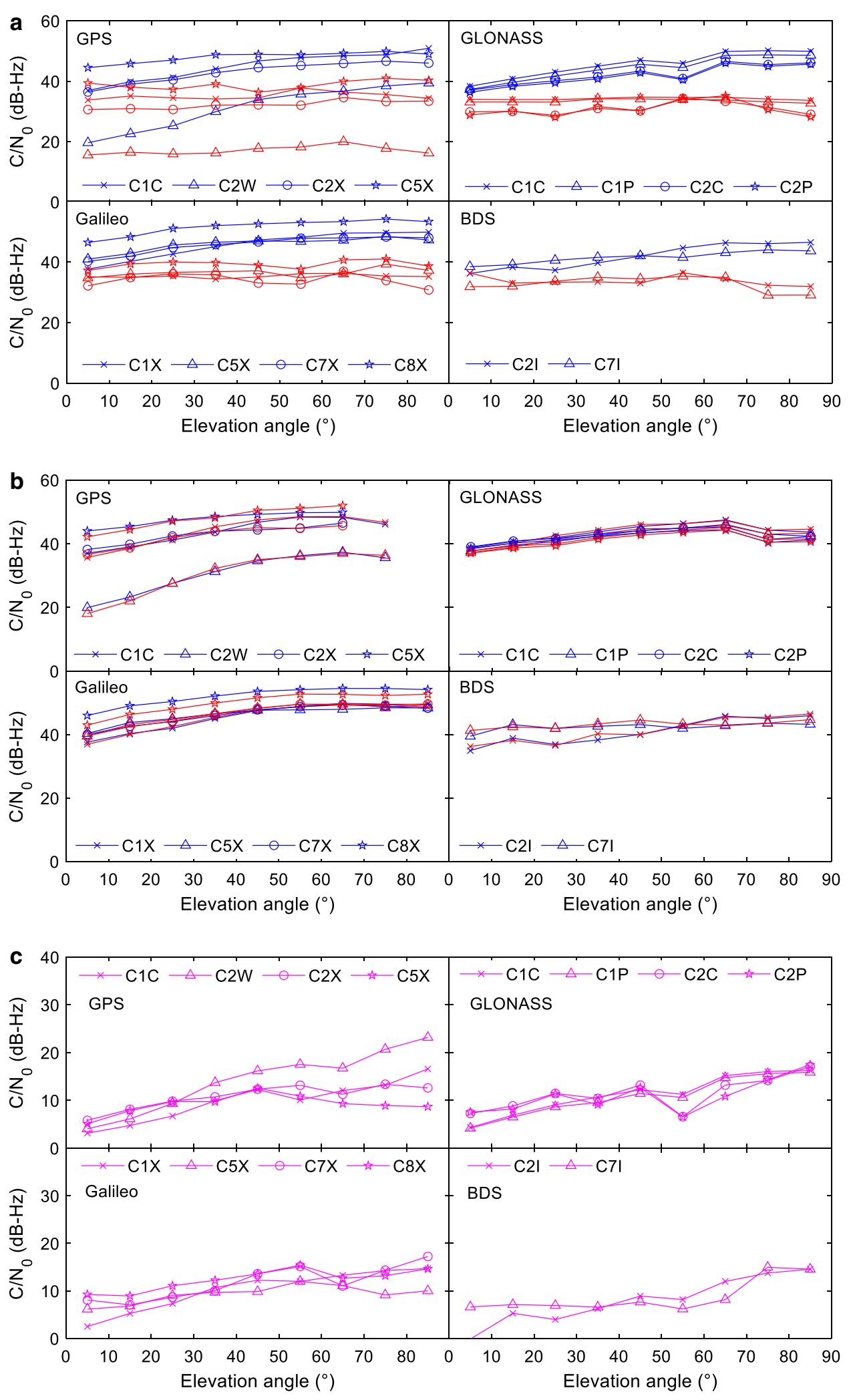
Table 3 Cycle slip statistics for GPS, GLONASS, Galileo, and BDS signals tracked by the two GNSS receivers in the experiment during period 1

\begin{tabular}{llll}
\hline GNSS & $\begin{array}{l}\text { Used observations } \\
\text { for cycle detection }\end{array}$ & $\begin{array}{l}\text { Receiver 1 } \\
\text { (without glass) }\end{array}$ & $\begin{array}{l}\text { Receiver 2 } \\
\text { (with glass) }\end{array}$ \\
\hline GPS & C1C-C2W/L1C-L2W & 7 & 49 \\
& C1C-C2X/L1C-L2X & 4 & 96 \\
& C1C-C5X/L1C-L5X & 4 & 57 \\
GLONASS & C1C-C2C/L1C-L2C & 8 & 230 \\
& C1P-C2P/L1P-L2P & 16 & 159 \\
\multirow{3}{*}{ Galileo } & C1X-C5X/L1X-L5X & 7 & 45 \\
& C1X-C7X/L1X-L7X & 5 & 46 \\
\multirow{2}{*}{ BDS } & C1X-C8X/L1X-L8X & 4 & 44 \\
\hline
\end{tabular}

It is noted that the RMS of TECR for Galileo is significantly lower than those of the others. This is explained by two possibilities. A potential reason is that Galileo observations exhibit better signal quality (Gioia et al. 2015). Furthermore, based on error propagation law, the theoretical accuracy of TECR is also related to the frequencies of GNSS observations. With respect to Eqs. (1)-(2), the theoretical TECR accuracy is calculated using the following equations:

$$
\begin{aligned}
& m_{P}= \pm k \delta_{P} \\
& m_{\varphi}= \pm k \delta_{\varphi} \\
& k=\frac{2 f_{1}^{2}}{40.28 \times 10^{16}(1-\gamma) \Delta t}
\end{aligned}
$$

where $m_{P}$ and $m_{\phi}$ denote the theoretical accuracy of TECR derived from pseudorange and carrier phase observations, respectively; and $\delta_{P}$ and $\delta_{\phi}$ denote the accuracy of pseudorange and carrier phase observations, respectively.

The values of $k$ and the corresponding TECR accuracies for different GNSS constellations are calculated using Eqs. (3)-(5), as shown in Table 5. The results indicate that the amplification factor $\mathrm{k}$ for Galileo is the lowest when compared to others. Therefore, theoretically, the RMSE error TECR calculated using Galileo observations is lower than those derived from other satellite systems, i.e., GPS, GLONASS, and BDS.

\section{Analysis of number of tracked satellites}

The number of satellites tracked by the two receivers at each epoch over the two periods is shown in Fig. 5. In the study, it is defined that the GNSS satellite is visible at one epoch when the observation types (GPS: C1C/ L1C, C2W/L2W; GLONASS: C1C/L1C, C2C/L2C; Galileo: C1X/L1X, C5X/L5X; BDS: C2I/L2I, C7I/L7I) for the GNSS satellite are all available at that epoch. Figure 5a shows that receiver 1 can observe approximately 37 GNSS satellites on average during period 1. Conversely, the number of visible GNSS satellites of receiver 2 is significantly lower than that of receiver 1 , and approximately only 13 satellites can be tracked over the period. However, as shown in Fig. 5b, the number of visible satellites of both receivers exhibit a good agreement during period 2. Specifically, the bottom plots in Fig. 5a, b show the difference in number of visible satellites between two receivers. We consider the number of visible satellites of receiver 1 as the reference. Approximately $65 \%$ of GNSS satellites of receiver 2 are lost owing to HST glass in period 1. At approximately 4:30:00, neither receiver 1 nor receiver 2 made observations. Thus a short data gap period exists in both receivers.

Additionally, the average number of tracked satellites for different GNSS constellations during the two periods are listed in Table 6. As shown in the Table 6 the number of tracked satellites of receiver 2 are significantly fewer than that of receiver 1 owing to the loss of signals resulting from the blocking of HST window glass during period 1. Based on the statistic results given in Table 6, during period 1, 37 GNSS satellites are tracked by receiver 1 while the number of tracked satellites by receiver 2 is 13. Conversely, receiver 1 and receiver 2 tracked similar number of GNSS satellites (36 and 37, respectively) during period 2.

\footnotetext{
(See figure on next page.)

Fig. 4 TECR derived from pseudorange and carrier phase observations of GPS, GLONASS, Galileo, and BDS signals as tracked by receiver 1 (left column) and receiver 2 (right column) during test period 1 (GPS time: 3:00:00-9:00:00) (a and b) and test period 2 (GPS time: 11:00:00-14:00:00) (c and $\mathbf{d}$ ). a TECR derived from GNSS pseudorange observations of receiver 1 (without HST window glass, left column) and receiver 2 (with HST window glass, right column) during period 1; b TECR derived from GNSS carrier phase observations of receiver 1 (without HST window glass, left column) and receiver 2 (with HST window glass, right column) during period 1; c TECR derived from GNSS pseudorange observations of receiver 1 (without HST window glass, left column) and receiver 2 (without HST window glass, right column) during period 2; d TECR derived from GNSS carrier phase observations of receiver 1 (without HST window glass, left column) and receiver 2 (without HST window glass, right column) during period 2
} 

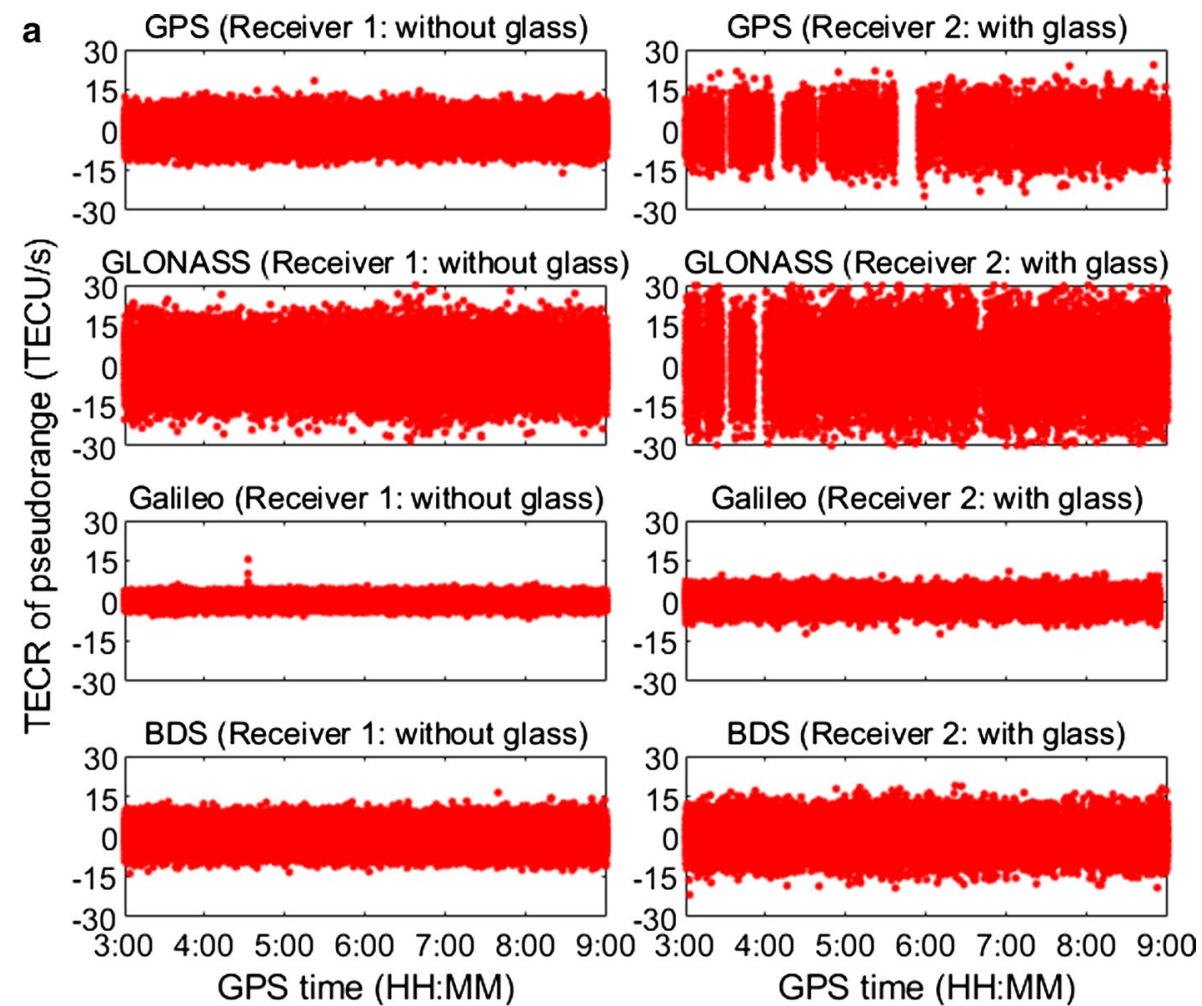

GPS time (HH:MM)

GPS time (HH:MM)
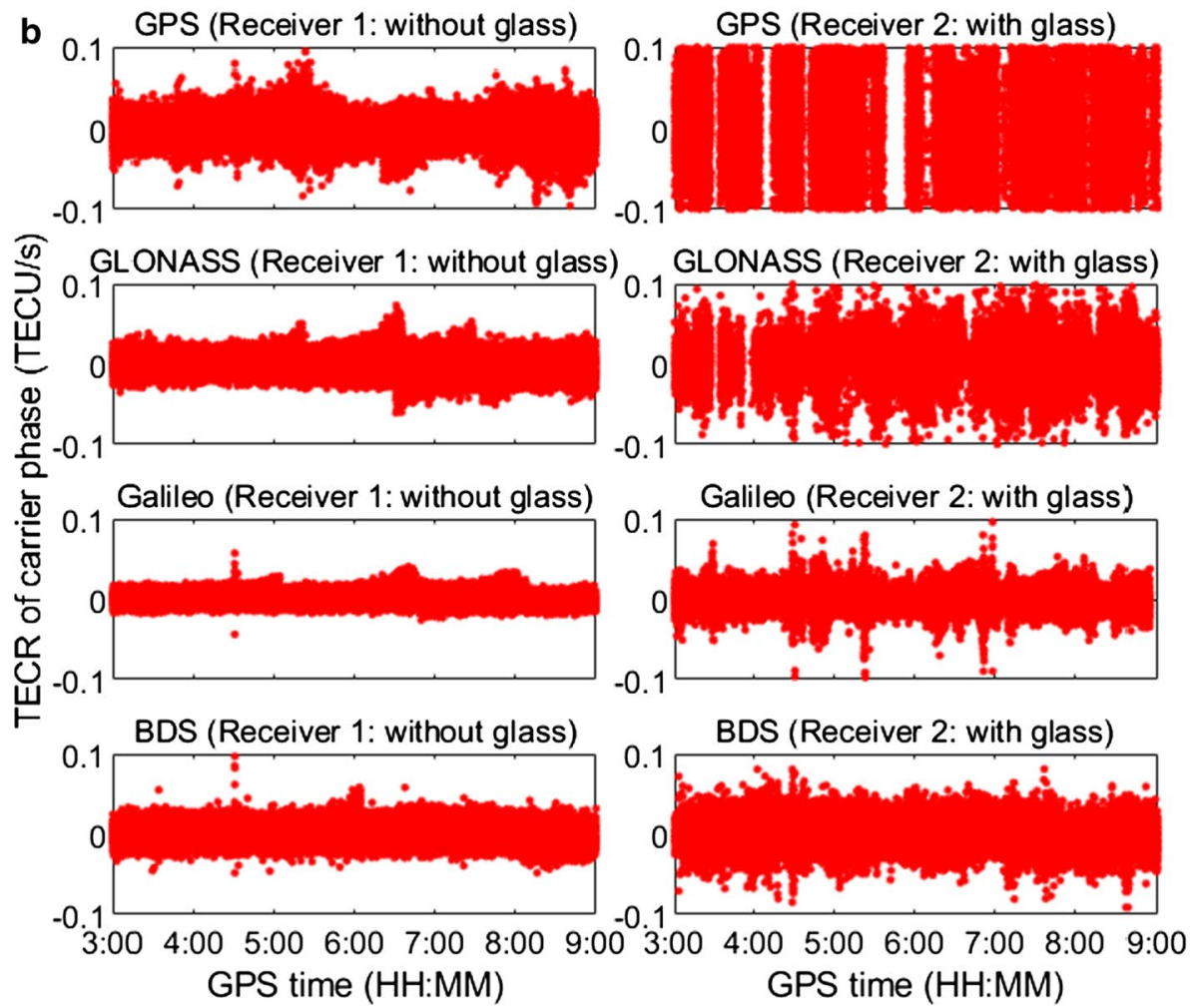

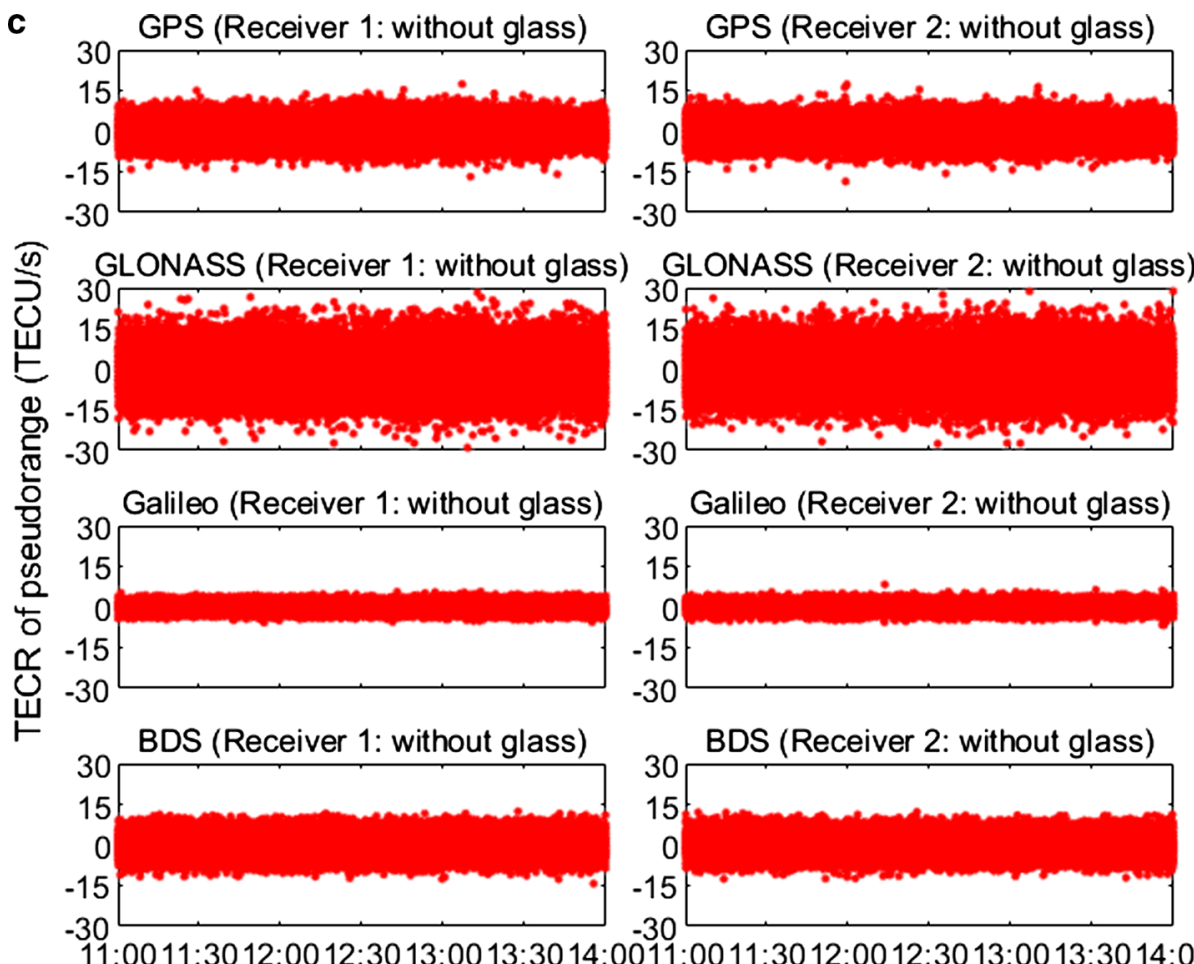

GLONASS (Receiver 2: without glass)
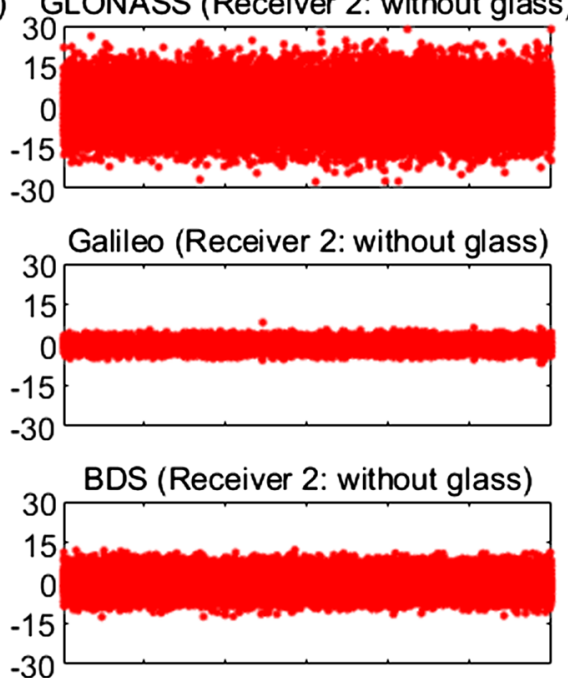
GPS time (HH:MM)

GPS time (HH:MM)
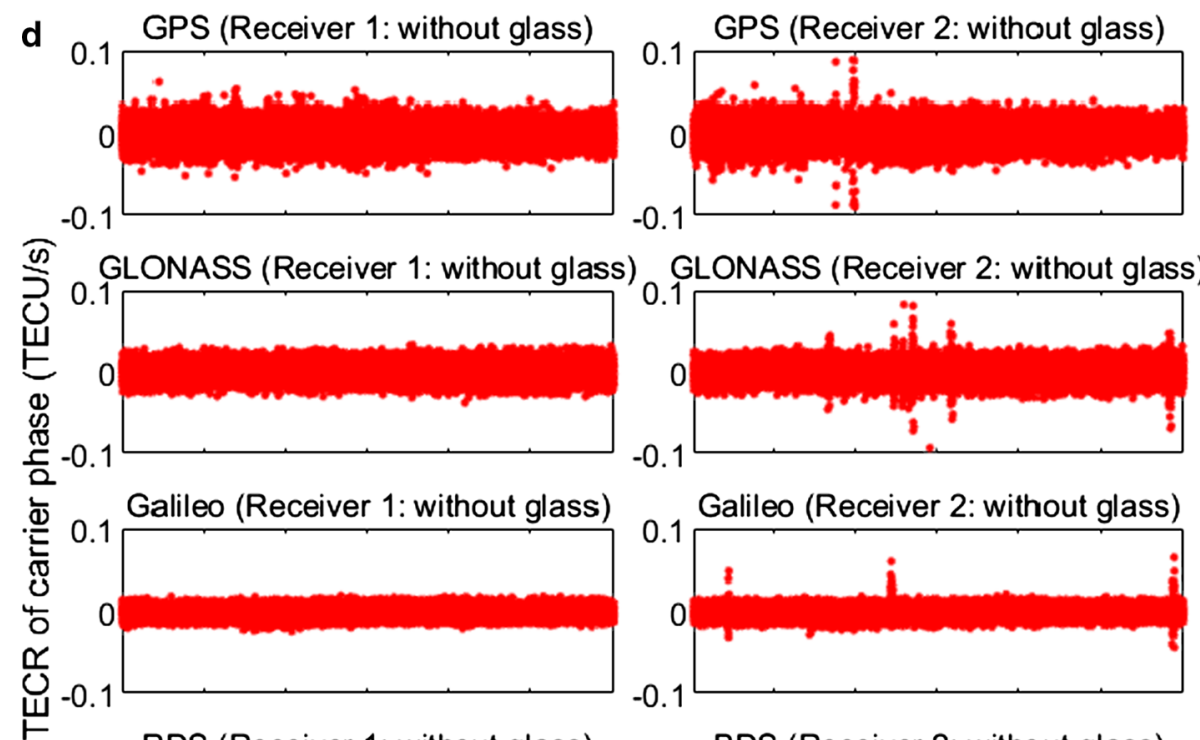

) GLONASS (Receiver 2: without glass)
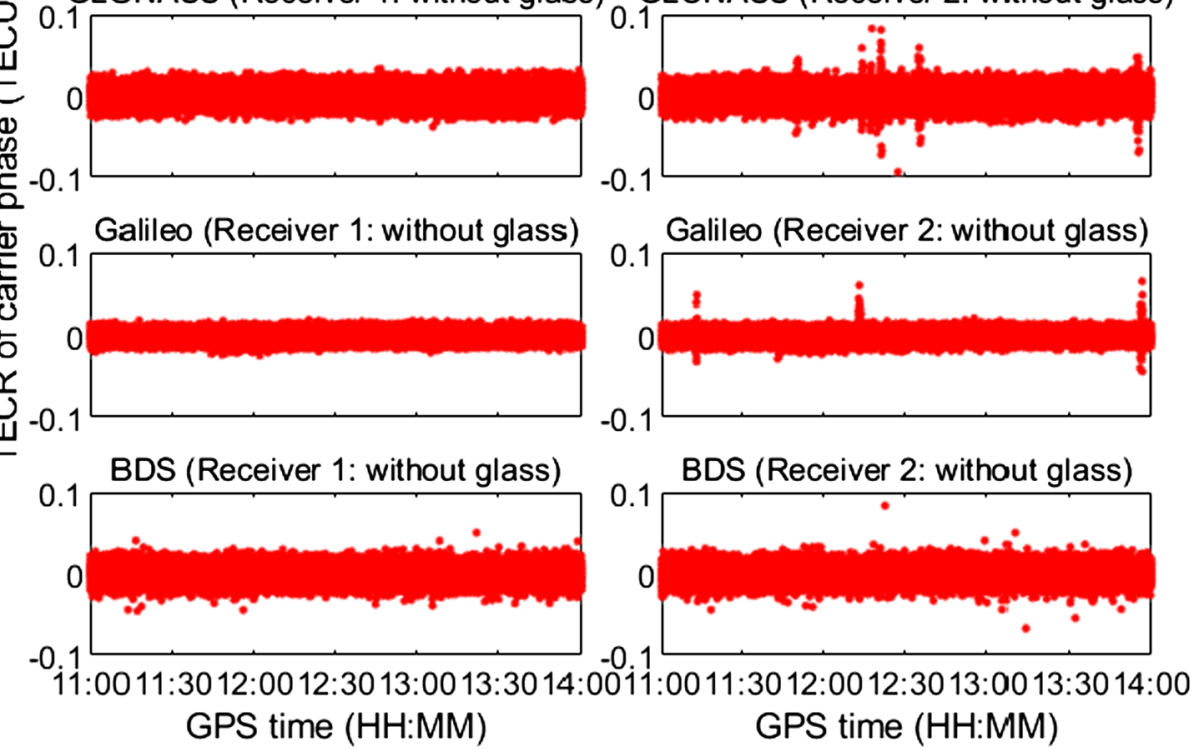

Fig. 4 continued 
Table 4 RMS of TECR that are calculated from different observation combinations during period 1 (GPS time: 3:00:009:00:00)

\begin{tabular}{|c|c|c|c|c|c|}
\hline \multirow[t]{2}{*}{ GNSS } & \multirow[t]{2}{*}{ Observations used } & \multicolumn{2}{|c|}{ RMS of TECR of pseudorange } & \multicolumn{2}{|c|}{ RMS of TECR of carrier phase } \\
\hline & & $\begin{array}{l}\text { Receiver } 1 \text { (without } \\
\text { glass) }\end{array}$ & Receiver 2 (with glass) & $\begin{array}{l}\text { Receiver } 1 \text { (without } \\
\text { glass) }\end{array}$ & Receiver 2 (with glass) \\
\hline GPS & C1C-C2W/L1C-L2W & 3.4 & $5.5(2.1,62 \%)$ & 0.013 & $0.072(0.059,454 \%)$ \\
\hline GLONASS & C1C-C2C/L1C-L2C & 6.4 & $9.6(3.2,50 \%)$ & 0.011 & $0.025(0.014,127 \%)$ \\
\hline Galileo & C1X-C5X/L1X-L5X & 1.4 & $2.3(0.9,64 \%)$ & 0.007 & $0.012(0.005,71 \%)$ \\
\hline BDS & C2I-C7I/L2I-L7| & 3.0 & $4.5(1.5,50 \%)$ & 0.009 & $0.015(0.006,67 \%)$ \\
\hline
\end{tabular}

Decimal numbers and percentages in parentheses correspond to increases in TECR RMS of receiver 2 relative to receiver 1 and the percentage of increase, respectively. Unit: TECU/s

Table 5 Theoretical accuracy of TECR for GNSS observations: GPS C1C-C2W/L1C-L2W, GLONASS C1C-C2C/ L1C-L2C, Galileo C1X-C5X/L1X-L5X, and BDS C2I-C7I/L2IL7I

\begin{tabular}{llll}
\hline GNSS & $\mathbf{k}$ & $\boldsymbol{m}_{\boldsymbol{p}}$ (TECU/s) & $\boldsymbol{m}_{\boldsymbol{\varphi}}$ (TECU/s) \\
\hline GPS C1C-C2W/L1C-L2W & 19.0 & 5.7 & 0.019 \\
GLONASS C1C-C2C/L1C-L2C & $19.4-19.6$ & $5.8-5.9$ & $0.019-0.020$ \\
Galileo C1X-C5X/L1X-L5X & 15.5 & 4.7 & 0.015 \\
BDS C2I-C7I/L2I-L71 & 18.0 & 5.4 & 0.018 \\
\hline
\end{tabular}

All GNSS pseudorange values are assumed to exhibit an accuracy of $\delta_{p}=0.3 \mathrm{~m}$ and $\delta_{\varphi}=0.001 \mathrm{~m}$ for carrier phase observations

\section{Analysis of PPP performance and GDOP}

A GPS/GLONASS PPP test is conducted using observations from the two receivers to further evaluate the degradation influence of HST window glass on GNSS signals. We use the Canadian Spatial Reference System (CSRS) online PPP services (http://www.geod.nrcan.gc. $\mathrm{ca} /$ ) to provide PPP solutions in the test because it can process single- or dual-frequency observations in static or kinematic PPP mode (Héroux et al. 2006). The online PPP service uses the International GNSS Service (IGS) precise clock and orbit products in the calculation. The results indicate that it can provide dual-frequency PPP results with an accuracy of 1-2 cm even at a millimeter scale in static mode (Guo et al. 2017). With respect to kinematic PPP mode, it realizes a positioning accuracy in the range of centimeters to a few decimeters depending on the quality of observations (El-Mowafy 2011).

In the test, GPS C1C/L1C and GLONASS C1C/L1C observations are used for single-frequency PPP. GPS $\mathrm{C} 1 \mathrm{C} / \mathrm{L} 1 \mathrm{C}, \mathrm{C} 2 \mathrm{~W} / \mathrm{L} 2 \mathrm{~W}$ and GLONASS C1C/L1C, C2C/ $\mathrm{L} 2 \mathrm{C}$ are selected for dual-frequency PPP. To obtain the reference values for the PPP solution evaluation, observations (GPS C1C/L1C, C2W/L2W; GLONASS C1P/L1P, $\mathrm{C} 2 \mathrm{P} / \mathrm{L} 2 \mathrm{P})$ over period 2 are used to produce the static PPP results. Figure 6 shows the GPS/GLONASS singleand dual-frequency static PPP results, for two receivers during period 1. Figure 7 shows the kinematic PPP results in which the static data are treated as kinematic data and processed in a kinematic mode. The CSRS-PPP adopts a backward smoothing strategy for kinematic PPP processing. Therefore, a positioning convergence process is not observed in Fig. 7.

As shown in the figures, the PPP performance of receiver 2 is evidently weaker than that of the receiver 1 in both static and kinematic PPP modes. Additionally, as shown in both Figs. 6 and 7, the positioning results using dual-frequency data are even worse than those using single-frequency data. This is because any loss of GPS/GLONASS L1 or L2 observations disables dual-frequency positioning. However, in the singlefrequency positioning mode, the loss of L2 observation does not have any effect as only L1 data are used. Therefore, dual-frequency PPP exhibits a higher chance to obtain data gap, and thus it is more difficult to fix carrier phase ambiguities. This explains the poorer results of dual-frequency positioning when compared to single-frequency positioning. Specifically, in the dual-frequency kinematic PPP mode, approximately $85 \%$ of epochs do not produce PPP solution output as shown in the Fig. 7d. As shown in Fig. 6d, in the dualfrequency static PPP mode, many epochs do not produce a valid PPP solution output although the situation is better than the dual-frequency kinematic case.

Table 7 lists the RMS of PPP errors in the east, north, up, and three-dimensional (3D) directions. Given that static PPP results is not backward smoothed, only the positioning results in the last $2 \mathrm{~h}$ (GPS time: 7:00:009:00:00) are used for positioning statistics. All the epochs are used in the kinematic positioning results.

Table 7 shows that receiver 1 (in the open-sky environment) single-frequency and dual-frequency static PPP 3D accuracies are $0.212 \mathrm{~m}$ and $0.025 \mathrm{~m}$, respectively. The corresponding single-frequency and dualfrequency kinematic PPP 3D accuracies are $0.264 \mathrm{~m}$ and $0.045 \mathrm{~m}$, respectively. Conversely, receiver 2 (covered 

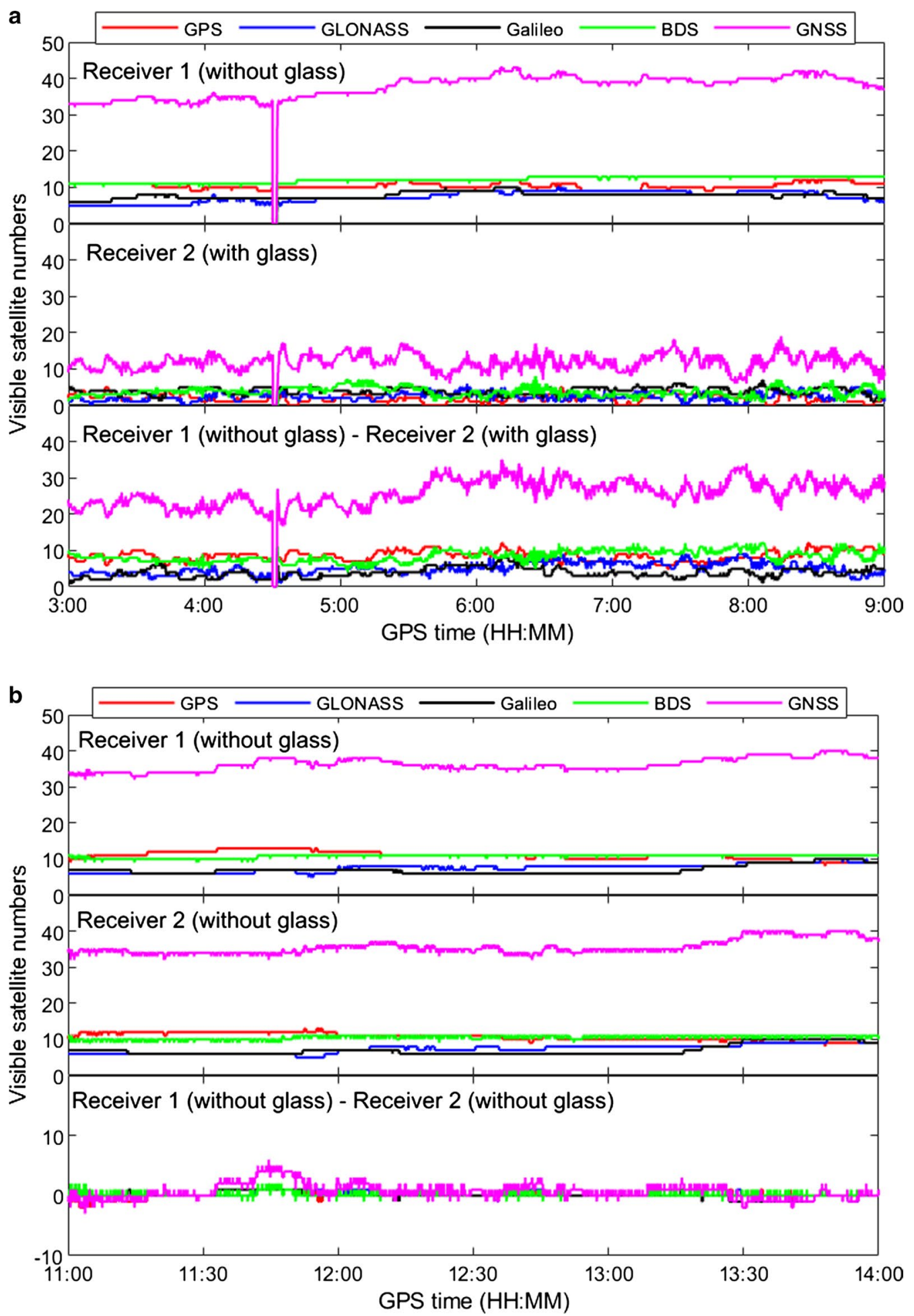

Fig. 5 Number of tracked GNSS satellites of two receivers during the two test periods. GNSS denotes a combination of GPS, GLONASS, Galileo, and BDS. a Number of tracked satellites of receiver 1 (without glass, top) and receiver 2 (with glass, middle) and their difference (bottom) during test period 1; b Number of tracked satellites of receiver 1 (without glass, top) and receiver 2 (without glass, middle) and their difference (bottom) during test period 2 
Table 6 Average number of visible satellites of two receivers during two test periods

\begin{tabular}{|c|c|c|c|c|c|c|}
\hline Periods & Receivers & GPS & GLONASS & Galileo & BDS & GNSS \\
\hline \multirow{2}{*}{$\begin{array}{l}\text { Period } 1 \text { (GPS time: } \\
\text { 3:00:00-9:00:00) }\end{array}$} & Receiver 1 (without glass) & 10 & 7 & 8 & 12 & 37 \\
\hline & Receiver 2 (with glass) & 2 & 3 & 4 & 4 & 13 \\
\hline \multirow{2}{*}{$\begin{array}{l}\text { Period 2 (GPS time: } \\
\text { 11:00:00-14:00:00) }\end{array}$} & Receiver 1 (without glass) & 11 & 7 & 7 & 11 & 36 \\
\hline & Receiver 2 (without glass) & 11 & 8 & 7 & 11 & 37 \\
\hline
\end{tabular}

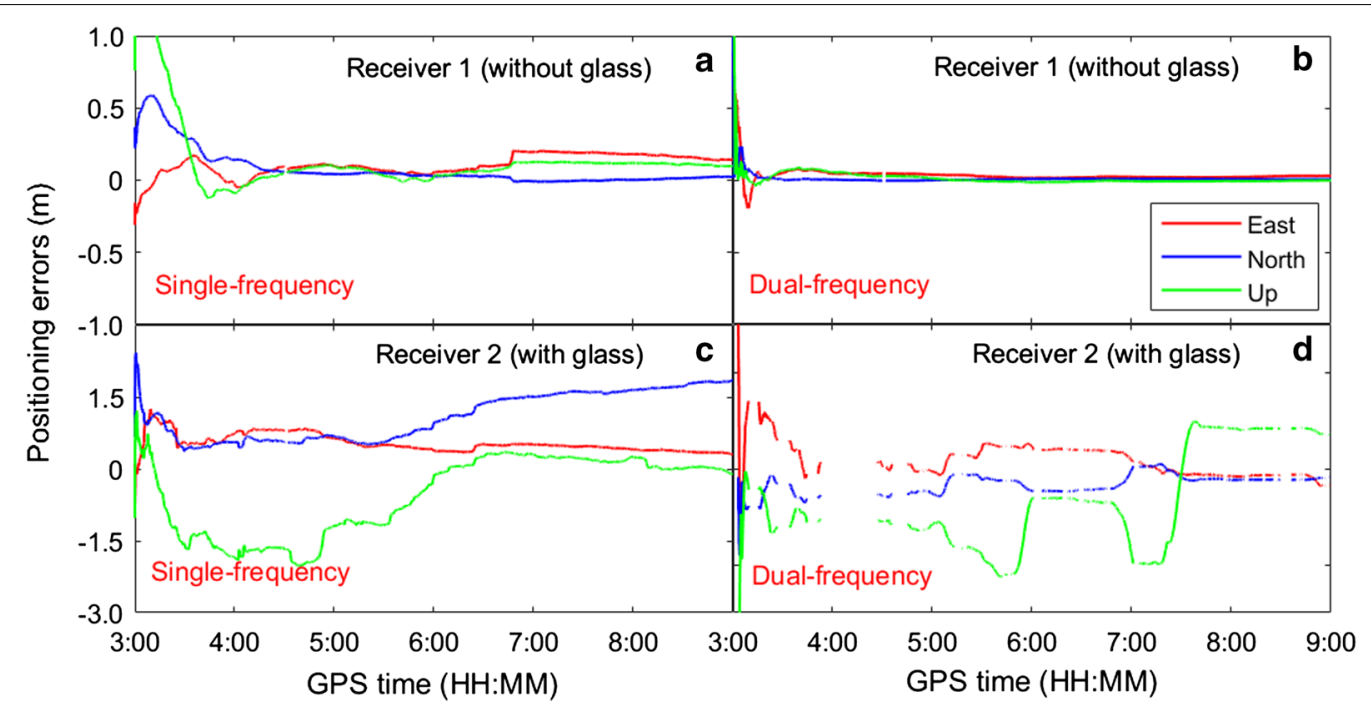

Fig. 6 GPS/GLONASS single- and dual-frequency static positioning results for the two receivers during period 1

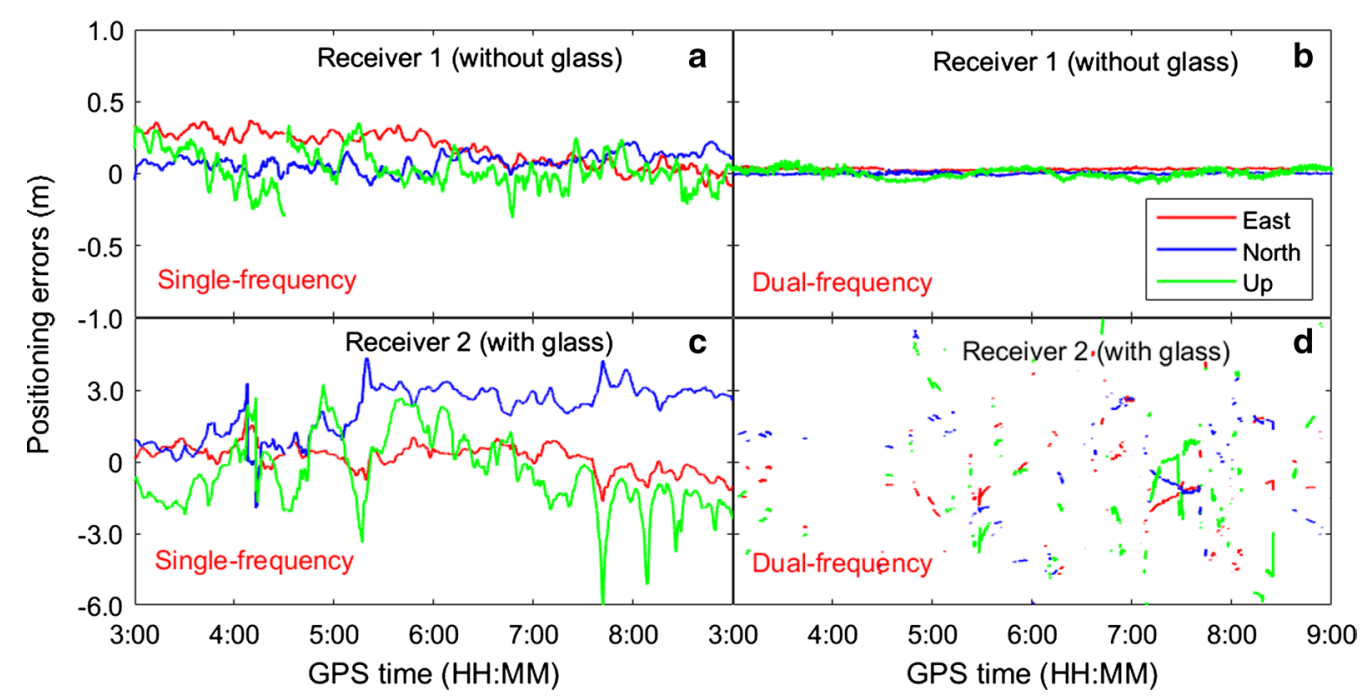

Fig. 7 GPS/GLONASS single and dual-frequency kinematic positioning results for the two receivers during period 1

by the HST window glass) exhibits significantly larger 3D positioning errors. Single-frequency and dualfrequency static PPP 3D accuracies are $1.728 \mathrm{~m}$ and $1.184 \mathrm{~m}$, respectively. With respect to kinematic PPP, the single-frequency and dual-frequency $3 \mathrm{D}$ accuracies are $2.934 \mathrm{~m}$ and $4.866 \mathrm{~m}$, respectively. The figures indicate that in static PPP the receiver 2 (with HST window glass) exhibits a degradation of $1.516 \mathrm{~m}$ and $1.159 \mathrm{~m}$ 
Table 7 RMS statistics of GPS/GLONASS single-frequency (SF) and dual-frequency (DF) static and kinematic PPP positioning errors (unit: $\mathbf{m}$ )

\begin{tabular}{|c|c|c|c|c|c|}
\hline PPP mode & Receivers & East & North & Up & $3 D$ \\
\hline \multirow[t]{2}{*}{ SF static PPP } & $\begin{array}{l}\text { Receiver } 1 \text { (without } \\
\text { glass) }\end{array}$ & 0.177 & 0.012 & 0.116 & 0.212 \\
\hline & Receiver 2 (with glass) & 0.419 & 1.668 & 0.163 & 1.728 \\
\hline \multirow[t]{2}{*}{ SF kinematic PPP } & $\begin{array}{l}\text { Receiver } 1 \text { (without } \\
\text { glass) }\end{array}$ & 0.209 & 0.100 & 0.128 & 0.264 \\
\hline & Receiver 2 (with glass) & 0.579 & 2.392 & 1.597 & 2.934 \\
\hline \multirow[t]{2}{*}{ DF static PPP } & $\begin{array}{l}\text { Receiver } 1 \text { (without } \\
\text { glass) }\end{array}$ & 0.023 & 0.006 & 0.008 & 0.025 \\
\hline & Receiver 2 (with glass) & 0.142 & 0.195 & 1.159 & 1.184 \\
\hline \multirow[t]{2}{*}{ DF kinematic PPP } & $\begin{array}{l}\text { Receiver } 1 \text { (without } \\
\text { glass) }\end{array}$ & 0.032 & 0.008 & 0.031 & 0.045 \\
\hline & Receiver 2 (with glass) & 2.171 & 2.336 & 2.675 & 4.866 \\
\hline
\end{tabular}

in single-frequency and dual-frequency positioning, respectively. In kinematic $\mathrm{PPP}$, the $3 \mathrm{D}$ accuracy degradation is $2.670 \mathrm{~m}$ and $4.821 \mathrm{~m}$ for single-frequency and dual-frequency positioning, respectively.

The CSRS-PPP also provides epoch-by-epoch GDOP value for each GNSS receiver. Figure 8 shows the GDOP of both receivers in different positioning modes over the period 1. Given the different numbers of tracked satellites, the GDOP of two receivers exhibit a significant difference over the period. In all the modes, the GDOP value of receiver 2 (with HST window glass) significantly exceeds that of receiver 1 . Specifically, for dual-frequency PPP, the GDOP of receiver 2 exceeds 4 in most time while GDOP of receiver 1 is maintained below 2. Furthermore, the results reveal that the GDOP of dual-frequency solution exceeds that of single-frequency solution. This is because fewer satellites are used in the dual-frequency case when compared to that in the single-frequency case.

\section{Conclusions}

A field experiment was conducted to investigate the attenuation impact of HST window glass on GNSS signals. Two GNSS receivers used for the experiment had the same model, and they were separated by merely a few meters to ensure they had the same observation environment. One of the receivers was covered by a piece of HST window glass, whereas the other receiver was in an opensky environment. After analyzing the GNSS signals, the following conclusions were drawn.

1. HST window glass significantly affects GNSS signal reception, which can lead to signal degradation and even loss of tracking. With respect to GPS, GLONASS, Galileo, and BDS, the signal loss rates are approximately $39 \%, 56 \%, 49 \%$, and $59 \%$, respectively. Additionally, the tracked GNSS signals are also subject to significant signal strength degradation up to $20 \mathrm{~dB}-\mathrm{Hz}$.

2. Significant signal degradation leads to many more cycle slips. Specifically, 44-230 cycle slips are detected for the receiver covered with the HST window glass while only 16 cycle slips or less are detected for the receiver in the open-sky environment.

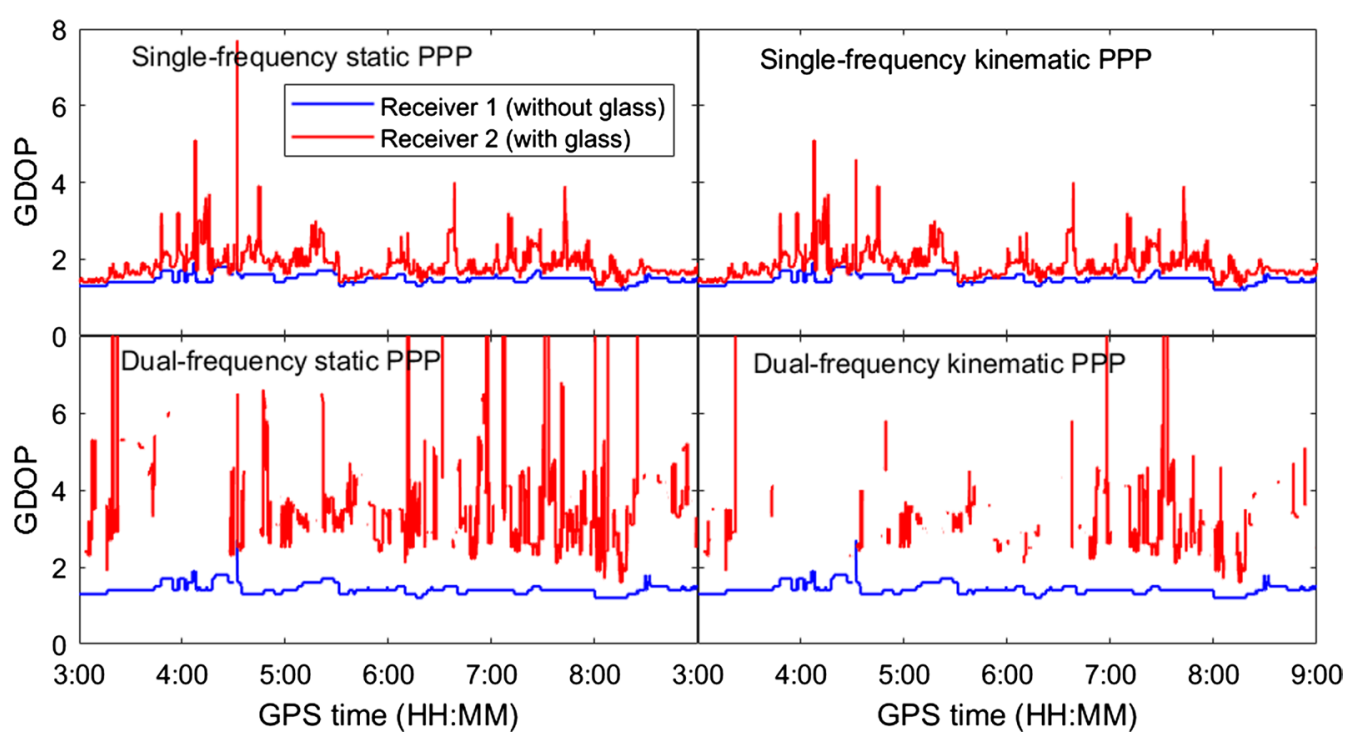

Fig. 8 GDOP of receiver 1 (without HST window glass, blue line) and receiver 2 (with HST window glass, red line) in different GPS/GLONASS PPP modes during period 1 
3. The number of satellites tracked by the receiver with HST window glass is approximately $65 \%$ lower than that of the receiver in the open-sky environment.

4. The PPP results indicate that HST window glass can result in 3D positioning degradations of $1.516 \mathrm{~m}$ and $1.159 \mathrm{~m}$ for single-frequency and dual-frequency static PPP, respectively. With respect to single-frequency and dual-frequency kinematic PPP, degradation due to the HST glass can reach $2.670 \mathrm{~m}$ and $4.821 \mathrm{~m}$, respectively.

\section{Competing interests}

The authors declare that they have no competing interests.

\section{Author details}

${ }^{1}$ Department of Land Surveying and Geo-Informatics (LSGI), The Hong Kong Polytechnic University (PolyU), 181 Chatham Road South, Hung Hom, Kowloon, Hong Kong, People's Republic of China. ${ }^{2}$ Research Institute for Sustainable Urban Development, The Hong Kong Polytechnic University (PolyU), 181 Chatham Road South, Hung Hom, Kowloon, Hong Kong, People's Republic of China. ${ }^{3}$ Department of Surveying and Geo-Informatics, Faculty of Geosciences and Environmental Engineering, Southwest Jiaotong University, West District of Chengdu High-Tech Park, Chengdu 611756, People's Republic of China.

Received: 24 November 2019 Accepted: 16 March 2020

Published online: 13 April 2020

\section{References}

GNSS: global navigation satellite systems; HST: high speed train; CORS: continuously operating reference stations; $\mathrm{C} / \mathrm{N}_{0}$ : carrier-to-noise ratio; TECR: total electron contents rate; PPP: precise point positioning; GDOP: geometric dilution of precision; RMS: root mean square; CSRS: Canadian spatial reference system; IGS: international GNSS service; 3D: three-dimensional.

\section{Acknowledgements}

The authors acknowledge grant supports from the National Natural Science Foundation of China (NSFC, No. 41730109), the Hong Kong Research Grants Council (RGC) General Research Fund (GRF) (B-Q52W RGC/Gov No. PolyU 152149/16E; and B-Q61L RGC/Gov No. PolyU 152222/17E) and the support from the Emerging Frontier Area (EFA) Scheme of Research Institute for Sustainable Urban Development (RISUD) of the Hong Kong Polytechnic University (No. 1-BBWJ). The authors also appreciate funding support by the Innovation and Technology Commission of Hong Kong SAR Government to the Hong Kong Branch of National Rail Transit Electrification and Automation Engineering Technology Research Center (Project No. 1-BBYH).

\section{Authors' contributions}

ZL proposed, designed, and funded the experiment. He revised and controlled the overall quality of the study. YG analyzed and processed experiment data and prepared the draft of the study. LZ conducted the experiment and collected experimental data. All authors read and approvedthe final manuscript.

\section{Authors' Information}

Zhizhao Liu is currently an Associate Professor at the Department of Land Surveying and Geo-Informatics (LSGI), The Hong Kong Polytechnic University (PolyU), Hong Kong, P. R. China. He received his B.Sc. in Surveying Engineering from the Jiangxi University of Science and Technology, China, in 1994 and an M.Sc. in Geodesy from the Wuhan University, China, in 1997. He earned his Ph.D. in Geomatics Engineering from the University of Calgary, Canada, in 2004. His research interests include new algorithm development for precise Global Positioning System (GPS) and global navigation satellite system (GNSS), GPS/GNSS precise point positioning, ionosphere modeling and scintillation monitoring, tropospheric modeling, and GPS/GNSS meteorology.

Yangzhao Gong is currently a Ph.D. student at the Department of Land Surveying and Geo-Informatics (LSGI), the Hong Kong Polytechnic University, Hong Kong, China. He received a B.S. from Xi'an University of Science and Technology in 2015, and an M.S. from Central South University in 2018. His research interests include GNSS precise point positioning and GNSS atmosphere monitoring.

Letao Zhou is an Associate Professor at Faculty of Geosciences and Environmental Engineering, Southwest Jiaotong University, Chengdu, China. He obtained his Ph.D. from the Southwest Jiaotong University of China in 2007. His research interests include multi-source fusion positioning navigation data processing methods and atmospheric remote sensing using GNSS data.

\section{Availability of data and materials}

GNSS observations used in the experiment were collected by Letao Zhou.
Ängskog, P., Bäckström, M., \& Vallhagen, B. (2015). Measurement of radio signal propagation through window panes and energy saving windows. In 2015 IEEE international symposium on electromagnetic compatibility (EMC) (pp. 74-79).

Asp, A., Sydorov, Y., Valkama, M., \& Niemelä, J. (2012). Radio signal propagation and attenuation measurements for modern residential buildings. IEEE Globecom Workshops, 2012, 580-584. https://doi.org/10.1109/GLOCO MW.2012.6477638. Towards Operational GPS Meteorology and the Second Network Workshop of the International GPS Service (IGS), 26(6), 373-383. https://doi.org/10.1016/ S1464-1895(01)00069-2.

El-Mowafy, A. (2011). Analysis of Web-based GNSS post-processing services for static and kinematic positioning using short data spans. Survey Review, 43(323), 535-549. https://doi.org/10.1179/003962611X13117748892074.

Gioia, C., Borio, D., Angrisano, A., Gaglione, S., \& Fortuny-Guasch, J. (2015). A Galileo IOV assessment: Measurement and position domain. GPS Solutions, 19(2), 187-199. https://doi.org/10.1007/s10291-014-0379-3.

Guo, F., Li, X., Zhang, X., \&Wang, J. (2017). Assessment of precise orbit and clock products for Galileo, BeiDou, and QZSS from IGS multi-GNSS experiment (MGEX). GPS Solutions, 21(1), 279-290. https://doi.org/10.1007/s1029 1-016-0523-3.

Gurtner, W., \& Estey, L. (2013). The receiver independent exchange format version 3.02 .

Hernández-Pajares, M., Juan, J. M., Sanz, J., Orus, R., Garcia-Rigo, A., Feltens, J., et al. (2009). The IGS VTEC maps: A reliable source of ionospheric information since 1998. Journal of Geodesy, 83(3), 263-275. https://doi.org/10.1007/s0019 0-008-0266-1.

Héroux, P., Kouba, J., Beck, N., Lahaye, F., Mireault, Y., Tétreault, P., et al. (2006). Space geodetic techniques and the Canadian spatial reference system evolution, status and possibilities. Geomatica, 60(2), 137-150.

Kjærgaard, M.B., Blunck, H., Godsk, T., Toftkjær, T., Christensen, D.L., \& Grønbæk, K. (2010). Indoor positioning using gps revisited. Pervasive. https://doi. org/10.1007/978-3-642-12654-3_3.

Liu, Z. (2011). A new automated cycle slip detection and repair method for a single dual-frequency GPS receiver. Journal of Geodesy, 85(3), 171-183. https ://doi.org/10.1007/s00190-010-0426-y.

Liu, Z., Chen, B., Yang, Z., Ding, X., \& Chen, W. (2016). Developing a wide-area GNSS-based Earth Observation Network (WAGEON) by integrating the GNSS and high speed train technologies. In Proceedings of the workshop on new technology for the construction and operational safety monitoring of highspeed railway. Chengdu: Southwest Jiaotong University.

Liu, Z., \& Gao, Y. (2004). Ionospheric TEC predictions over a local area GPS reference network. GPS Solutions, 8(1), 23-29. https://doi.org/10.1007/s1029 1-004-0082-x.

Seco-Granados, G., López-Salcedo, J., Jiménez-Baños, D., \& López-Risueño, G. (2012). Challenges in Indoor Global Navigation Satellite Systems: Unveiling its core features in signal processing. IEEE Signal Processing Magazine, 29(2), 108-131. https://doi.org/10.1109/MSP.2011.943410.
Bock, O., \& Doerflinger, E. (2001). Atmospheric modeling in GPS data analysis for high accuracy positioning. Proceedings of the First COST Action 716 Workshop 
Stone, W. C. (1997). Electromagnetic signal attenuation in construction materials. No. NIST Interagency/Internal Report (NISTIR)-6055.

Widenberg, B., \& Rodriguez, J. V. (2002). Design of energy saving windows with high transmission at $900 \mathrm{MHz}$ and $1800 \mathrm{MHz}$. (Technical Report LUTEDX/(TEAT7110/1-14/(2002); Vol. TEAT-7110).

Yang, Z., \& Liu, Z. (2016). Correlation between ROTI and lonospheric Scintillation Indices using Hong Kong low-latitude GPS data. GPS Solutions, 20(4) 815-824. https://doi.org/10.1007/s10291-015-0492-y.
Zhang, X., Wu, M., Liu, W., Li, X., Yu, S., Lu, C., et al. (2017). Initial assessment of the COMPASS/BeiDou-3: New-generation navigation signals. Journal of Geodesy, 91(10), 1225-1240. https://doi.org/10.1007/s00190-017-1020-3.

\section{Publisher's Note}

Springer Nature remains neutral with regard to jurisdictional claims in published maps and institutional affiliations.

\section{Submit your manuscript to a SpringerOpen ${ }^{\circ}$ journal and benefit from:}

- Convenient online submission

- Rigorous peer review

- Open access: articles freely available online

- High visibility within the field

- Retaining the copyright to your article

Submit your next manuscript at springeropen.com 